\title{
Structure of the propene-sulfur dioxide complex
}

\author{
Li-Wei Xu and Robert L. Kuczkowski \\ Department of Chemistry, The University of Michigan, Ann Arbor, Michigan 48109-1055
}

(Received 22 July 1993; accepted 14 September 1993)

\begin{abstract}
The rotational spectra of eight isotopomers of the propene $\cdot \mathrm{SO}_{2}$ complex have been observed with a Fourier transform microwave spectrometer. The rotational constants of the normal species are $A=4269.564 \mathrm{MHz}, B=1577.2661 \mathrm{MHz}$, and $C=1469.6335 \mathrm{MHz}$. The structure of the complex was derived from least-squares fitting of the 24 moments of inertia. It has a stacked, near-parallel planes configuration. The distance between the centers of mass of the two monomers is $3.26(5) \AA$. The sulfur atom is approximately above the propene double bond. The $\mathrm{C}_{2}$ axis of $\mathrm{SO}_{2}$ nearly eclipses the carbon-carbon single bond with the oxygen atoms towards the methyl group. The dipole moment of the complex was determined by Stark effect measurements to be $\mu=1.34(3) \mathrm{D}$. The binding energy is estimated to be $2.9 \mathrm{kcal} / \mathrm{mol}$ from the pseudodiatomic model. Both electrostatic and $a b$ initio calculations have been carried out to rationalize the structure and properties of the complex. The effect of methyl group substitution on the structures and properties of the ethylene $\cdot \mathrm{SO}_{2}$, propene $\cdot \mathrm{SO}_{2}$, and toluene $\cdot \mathrm{SO}_{2}$ complexes is discussed.
\end{abstract}

\section{INTRODUCTION}

Sulfur dioxide complexes form an important category of so-called weak charge transfer complexes. In particular, $\mathrm{SO}_{2} \cdot$ hydrocarbon complexes have been studied for over 40 $\mathrm{yr}^{1,2}$ Recently, a group of $\mathrm{SO}_{2} \cdot$ hydrocarbon complexes has been studied by high resolution spectroscopy and detailed structures derived for ethylene $\cdot \mathrm{SO}_{2},{ }^{3}$ acetylene $\cdot \mathrm{SO}_{2},{ }^{4}$ benzene $\cdot \mathrm{SO}_{2},{ }^{5}$ and tolucne $\cdot \mathrm{SO}_{2} \cdot{ }^{6}$ The complexes have a stacked configuration with the sulfur atom above the $\pi$-electron cloud of the hydrocarbon. In ethylene $\cdot \mathrm{SO}_{2}$ and acetylene $\cdot \mathrm{SO}_{2}$, the $\mathrm{C}_{2}$ axis of $\mathrm{SO}_{2}$ bisects the $\mathrm{C}-\mathrm{C}$ bonds at $90^{\circ}$. The two monomer planes are nearly parallel deviating from this by $14^{\circ}$ and $8^{\circ}$, respectively. In the benzene and toluene complexes, the $\mathrm{SO}_{2}$ is more tipped with the $\mathrm{SO}_{2}$ plane forming an angle of about $45^{\circ}$ and $35^{\circ}$, respectively, with the hydrocarbon plane. One striking feature of toluene $\cdot \mathrm{SO}_{2}$ is its asymmetry; the $\mathrm{C}_{2}$ axis of $\mathrm{SO}_{2}$ and the $\mathrm{C}-\mathrm{CH}_{3}$ bond axis of toluene form an angle of about $47^{\circ}$ with one S-O bond approximately aligned along the $\mathrm{C}-\mathrm{CH}_{3}$ bond suggesting an oxygenmethyl group interaction. In view of this methyl group effect, it seemed worthwhile to extend our investigations to the propene $\cdot \mathrm{SO}_{2}$ complex.

There has been no previous spectroscopic study on this complex. It is interesting that $\mathrm{SO}_{2}$ and propene form a copolymer under certain conditions, ${ }^{7}$ which is sometimes referred to as poly (propene sulfone). Efforts have been made to understand the mechanism of formation, structure, and properties of the polymer. No evidence for this reaction was observed in our experiments.

This paper reports the observation and analysis of the spectra of propene $\cdot \mathrm{SO}_{2}$ and its isotopomers. Least-squares fitting of the moments of inertia gave a structure with a stacked configuration. The two molecular planes are very close to parallel and the torsional angle between propene and $\mathrm{SO}_{2}$ is such that the $\mathrm{S}$ atom lies above the double bond and the $\mathrm{O}$ atoms are above the methyl group. The structure appears to be the result of a sulfur interaction with the $\pi$ bond and an oxygen interaction with the methyl group.

\section{EXPERIMENTAL DETAILS}

\section{A. Samples}

The propene $\cdot \mathrm{SO}_{2}$ complex was generated in a supersonic expansion of a gas mixture of roughly $1 \%$ propene and $1 \% \mathrm{SO}_{2}$ seeded in $98 \%$ of "first run" $\mathrm{Ne}-\mathrm{He}$ carrier gas $(\sim 80 \% \mathrm{Ne}, 20 \% \mathrm{He})$ at a total backing pressure of 1-2 atm. The spectrum was less intense when Ar was used as the carrier gas. The $\mathrm{S}^{18} \mathrm{O}_{2}$ transitions were observed using enriched $\mathrm{S}^{18} \mathrm{O}_{2}\left(99 \%{ }^{18} \mathrm{O}\right.$, Alfa Inorganics). The $\mathrm{S}^{18} \mathrm{O}^{16} \mathrm{O}$ sample was made by mixing equal amounts of $\mathrm{S}^{16} \mathrm{O}_{2}$ and $\mathrm{S}^{18} \mathrm{O}_{2}$ in a glass bulb. They exchange rapidly upon mixing to form a 2:1:1 mixture of $\mathrm{S}^{16} \mathrm{O}^{18} \mathrm{O}: \mathrm{S}^{16} \mathrm{O}_{2}: \mathrm{S}^{18} \mathrm{O}_{2}$. The spectrum of the ${ }^{34} \mathrm{~S}$ species was observed in its natural abundance of $4 \%$. The enriched propene-2- $d_{1}$ species $(98 \% \mathrm{D})$ was purchased from MSD Isotopes. The single- ${ }^{18} \mathrm{O}$, propene-2- $d_{1}$ double substituted isotopic transitions were observed starting with a mixture of $0.5 \% \mathrm{~S}^{16} \mathrm{O}_{2}$ and $0.5 \% \mathrm{~S}^{18} \mathrm{O}_{2}$ plus $1 \%$ of propene- $2-d_{1}$ in the carrier gas.

\section{B. Spectrometer}

A Balle-Flygare type Fourier transform microwave spectrometer ${ }^{8}$ was used to observe the rotational spectrum of the complex. The spectrometer operates between 7-18 $\mathrm{GHz}$ and has a modified Bosch fuel injector for a pulsed supersonic nozzle source. ${ }^{9}$ Timing of the gas and microwave pulses was coordinated to minimize Doppler splittings of the transitions. With this system, linewidths were typically $25-30 \mathrm{kHz}$ full width at half-maximum resulting from Doppler broadening. Center frequencies were usually 
TABLE I. Observed rotational transitions of propene $\cdot \mathrm{SO}_{2}(\mathrm{MHz})$.

\begin{tabular}{|c|c|c|c|c|c|c|c|}
\hline$J_{K_{\rho} K_{o}}$ & $J_{K_{p} K_{0}}^{\prime \prime}$ & $v_{\text {obs }}$ & $\Delta v^{\mathrm{a}}(\mathrm{kHz})$ & $J_{K_{p} K_{o}}^{\prime}$ & $J_{K_{\rho} K_{o}}^{\prime \prime}$ & $v_{\text {obs }}$ & $\Delta v(\mathrm{kHz})$ \\
\hline \multicolumn{4}{|c|}{$a$ type } & \multicolumn{4}{|c|}{$b$ type } \\
\hline & & & & $5_{24}$ & $5_{15}$ & 9056.834 & 2 \\
\hline $3_{13}$ & $2_{12}$ & 8976.854 & 0 & $6_{2 s}$ & $6_{16}$ & 9389.134 & -2 \\
\hline $3_{03}$ & 202 & 9127.719 & 0 & $4_{04}$ & $3_{13}$ & 9718.416 & -1 \\
\hline $3_{22}$ & 221 & 9140.046 & 2 & $7_{26}$ & $7_{17}$ & 9779.352 & -5 \\
\hline $3_{21}$ & 220 & 9152.630 & 0 & $3_{13}^{20}$ & 202 & 11564.610 & 2 \\
\hline $3_{12}$ & 2 & 9299.734 & 0 & $5_{05}$ & $4_{14}$ & 12923.636 & 3 \\
\hline 221 & 202 & 10987.553 & 2 & 221 & $1_{10}$ & 14278.163 & -3 \\
\hline $4_{14}$ & $3_{13}$ & 11965.207 & 5 & 220 & $1_{11}$ & 14388.947 & -3 \\
\hline $4_{04}$ & $3_{03}$ & 12155.304 & -2 & $4_{14}$ & $3_{03}$ & 14402.095 & 5 \\
\hline $4_{13}$ & $3_{12}$ & 12395.482 & 0 & & & $c$ type & \\
\hline 505 & $4_{04}$ & 15170.422 & 4 & $5_{24}$ & $5_{14}$ & 7443.623 & 8 \\
\hline $5_{24}$ & $4_{23}$ & 15225.454 & 8 & $4_{23}$ & $4_{13}$ & 7705.658 & 4 \\
\hline $5_{33}$ & $4_{32}$ & 15241.935 & -2 & $3_{22}$ & $3_{12}$ & 7917.197 & 0 \\
\hline $5_{23}$ & $4_{22}$ & 15287.670 & -4 & 221 & 211 & 8076.884 & -2 \\
\hline \multirow[t]{2}{*}{$5_{14}$} & $4_{13}$ & 15487.480 & -5 & 220 & $2_{12}$ & 8402.949 & 2 \\
\hline & & $b$ type & & $3_{21}$ & 3 & 8578.725 & 2 \\
\hline $6_{24}$ & $6_{15}$ & 7349.745 & -6 & $4_{22}$ & $4_{14}$ & 8828.808 & -3 \\
\hline $5_{23}$ & $5_{14}$ & 7552.926 & -3 & $6_{16}$ & $5_{24}$ & 8874.832 & -3 \\
\hline $4_{22}$ & $4_{13}$ & 7752.738 & -2 & $2_{11}^{10}$ & $1_{01}^{24}$ & 9001.197 & -2 \\
\hline $3_{21}^{22}$ & $3_{12}$ & 7932.932 & 0 & $5_{23}$ & $5_{15}$ & 9166.147 & 2 \\
\hline 220 & $2_{11}$ & 8080.036 & 0 & $6_{24}$ & $6_{16}$ & 9605.891 & 7 \\
\hline 221 & 2. & 8399.799 & 2 & $3_{12}$ & $2_{02}$ & 12210.397 & -1 \\
\hline $3_{22}$ & $3_{13}$ & 8562.989 & 1 & 220 & $1_{10}$ & 14281.313 & -3 \\
\hline 212 & $1_{01}$ & 8678.288 & 0 & 201 & $\mathbf{1}_{11}$ & 14385.798 & -2 \\
\hline $4_{23}$ & $4_{14}$ & 8781.726 & 0 & $4_{13}$ & $3_{03}$ & 15478.158 & -3 \\
\hline
\end{tabular}

${ }^{2} \Delta \nu=v_{\text {obs }}-v_{\text {calc }}$ in $\mathrm{kHz}$, where $v_{\text {calc }}$ was obtained with the constants in Table II.

reproducible to within $2-3 \mathrm{kHz}$. For the normal isotopic species, some of the transitions were broader than the typical linewidth and some showed splitting due to internal rotation tunneling effects of the methyl group. The transitions for the propene-2- $d_{1}$ isotopic species were fairly broad due to additional quadrupole splitting from deuterium. A so-called axial nozzle was used to resolve some of the internal rotation and quadrupole splittings. The gas expansion axis and microwave propagation direction are parallel with an axial nozzle orientation and perpendicular with the regular arrangement. In the case of the axial nozzle, the Doppler splitting was much larger $(50-90 \mathrm{kHz})$ and could be resolved easily while the Doppler broadening (i.c., line- width) decreased to $\sim 10 \mathrm{kHz}$. Hence, resolution improved with the axial nozzle and small splittings arising from internal rotation $(15-25 \mathrm{kHz})$ and from nuclear quadrupole effects (10-20 kHz) could be resolved.

Stark effect measurements were used to determine the $J$ quantum number of transitions during the initial assignment, and later on for determination of the dipole moment. The spectrometer is equipped with two parallel steel mesh plates $30 \mathrm{~cm}$ apart straddling the microwave cavity. ${ }^{10} \mathrm{Di}$ rect current voltages up to $9 \mathrm{kV}$ were applied with opposite polarities to each plate. The electric field at each voltage was calibrated on a daily basis using the $2_{01}{ }^{-1} 1_{11}$ transition of $\mathrm{SO}_{2} \cdot{ }^{11}$

TABLE II. Spectroscopic constants for the isotopic species of the propene $\cdot \mathrm{SO}_{2}$ complex. ${ }^{2}$

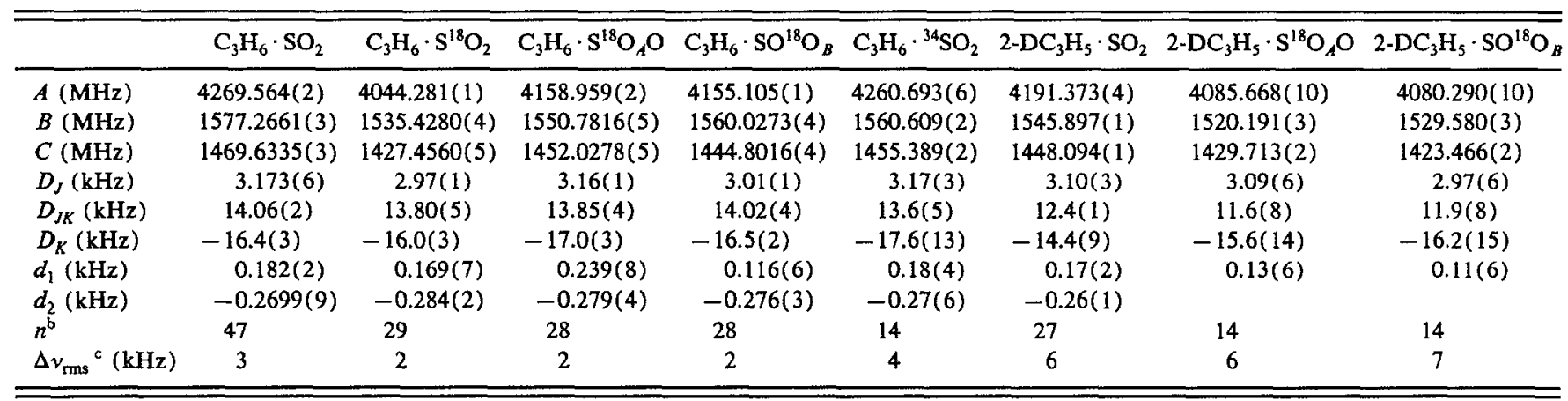

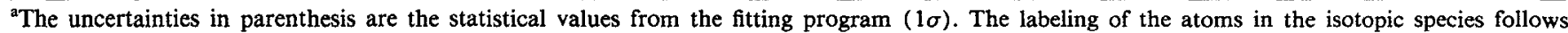
Fig. 1.

${ }^{b}$ Number of transitions in the fit.

${ }^{\mathrm{c}} \Delta v=v_{\text {obs }}-v_{\text {calc }}$. 


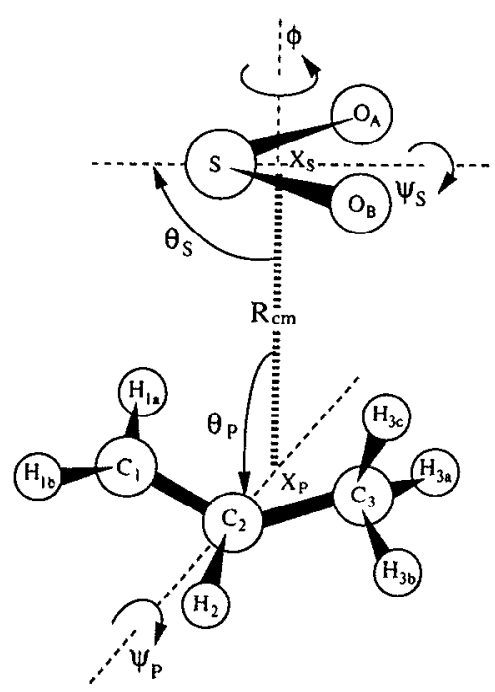

FIG. 1. Definition of the structural parameters employed in the structure fitting and atom labeling for the propene $\cdot \mathrm{SO}_{2}$ complex. $X_{S}$ and $X_{P}$ are the centers of mass of $\mathrm{SO}_{2}$ and propene, respectively. $R_{\mathrm{cm}}$ is the distance between $X_{S}$ and $X_{P}, \theta_{S}$ is the tilt angle of the $\mathrm{C}_{2}$ axis of $\mathrm{SO}_{2}$ with respect to $R_{\mathrm{cm}}$ and $\theta_{p}$ is formed between $R_{\mathrm{cm}}$ and $X_{F} C_{2}$ of propylene. The twist of the $\mathrm{SO}_{2}$ and propene planes with respect to $R_{\mathrm{cm}}$ are defined by the angles $\psi_{S}\left(\left\langle O_{B} S-X_{S}-X_{P}\right)\right.$ and $\psi_{P}\left(\left\langle C_{1}-C_{2}-X_{F} X_{S}\right)\right.$. The dihedral angle $\phi$ is the torsion between the two molecular planes. $\left(\left\langle\mathrm{S}-X_{S}-X_{F} \mathrm{C}_{2}\right)\right.$.

\section{RESULTS AND ANALYSIS}

\section{A. Spectrum}

Based on models similar to the structure of ethylene $\cdot \mathrm{SO}_{2}$, an initial search was made in the region 8.0-9.5 GHz, where many transitions were observed. With the aid of the Stark effect, a total of $14 a$-type, $18 b$-type, and $15 c$-type transitions were assigned to the propene $\cdot \mathrm{SO}_{2}$ dimer. Some of the transitions were broader than usual; several exhibited two barely resolved components. This broadening and splitting is caused by the internal rotation of the methyl group which will be discussed later. Since the splitting was very small $(15-25 \mathrm{kHz})$, we used a conventional Watson $S$-reduced Hamiltonian, $I^{r}$ representation ${ }^{12}$ to fit the spectrum to the average frequency of the two components for those lines with split-

TABLE III. Structural parameters from least-squares fits of the moments of inertia.

\begin{tabular}{lcc}
\hline \hline & Structure $\mathrm{I}^{\mathrm{a}}$ & ${\text { Structure } \mathrm{II}^{\mathrm{a}}}$ \\
\hline$\theta_{S} / \operatorname{deg}\left(\left\langle X_{P} X_{S} \mathrm{~S}\right)^{\mathrm{b}}\right.$ & $93.1(7)$ & $94.7(13)$ \\
$\theta_{P} / \operatorname{deg}\left(\left\langle X_{S} X_{F} C_{2}\right)\right.$ & $96.3(3)$ & $96.6(7)$ \\
$\psi_{S} / \operatorname{deg}\left(\left\langle\mathrm{O}_{B} S-X_{S} X_{P}\right)\right.$ & $89.9(2)$ & $88.5(4)$ \\
$\psi_{P} / \operatorname{deg}\left(\left\langle\mathrm{C}_{1}-\mathrm{C}_{2}-X_{P} X_{S}\right)\right.$ & $82.1(1)$ & $82.3(3)$ \\
$\phi / \operatorname{deg}\left(\left\langle\mathrm{S}-X_{S} X_{F} C_{2}\right)\right.$ & $-60.1(1)$ & $120.0(1)$ \\
$R_{\mathrm{cm}} / \AA$ & $3.2648(2)$ & $3.2649(4)$ \\
$\Delta I_{\mathrm{mm}} / \mathrm{amu} \AA^{2 c}$ & 0.07 & 0.15 \\
\hline \hline
\end{tabular}

Least-squares fit of 24 moments of inertia from the eight isotopic species. See text for a discussion of the two fits. Structure I is preferred by the authors.

bStructural parameters defined in Fig. 1.

${ }^{c} \Delta I=I_{x}$ (observed) $-I_{x}$ (calculated) for a given isotopic species. tings. The frequencies of the transitions are listed in Table I and the fitted rotational constants are listed in Table II.

The spectra of the isotopic species $\mathrm{C}_{3} \mathrm{H}_{6} \cdot \mathrm{S}^{18} \mathrm{O}_{2}$, $\mathrm{C}_{3} \mathrm{H}_{6} \cdot \mathrm{S}^{18} \mathrm{OO}, \quad \mathrm{C}_{3} \mathrm{H}_{6} \cdot \mathrm{SO}^{18} \mathrm{O}, \quad \mathrm{C}_{3} \mathrm{H}_{6} \cdot{ }^{34} \mathrm{SO}_{2}$, $\mathrm{CH}_{3} \mathrm{CDCH}_{2} \cdot \mathrm{SO}_{2}, \quad \mathrm{CH}_{3} \mathrm{CDCH}_{2} \cdot \mathrm{S}^{18} \mathrm{OO}, \quad$ and $\mathrm{CH}_{3} \mathrm{CDCH}_{2} \cdot \mathrm{SO}^{18} \mathrm{O}$ have also been observed. Their transitions are available as supplementary data ${ }^{13}$ and the derived rotational constants are listed in Tablc II. The spectra of the latter two double substituted species were obtained to try to resolve a structural ambiguity remaining after assigning the other six isotopic species. This will be discussed in the next section.

\section{B. Structure}

The presence of three selection rules, two single ${ }^{18} \mathrm{O}$ species, etc., indicate that propene $\cdot \mathrm{SO}_{2}$ has no symmetry planes. Based on this and on trial structures, the rotational constants are consistent with the stacked planes configuration.

In order to determine the exact structure of the complex, least-squares fits of the moments of inertia of all the isotopic species were carried out fixing the structures of each monomers to literature values. ${ }^{14}$ Six parameters are needed to define the structure of the propene $\cdot \mathrm{SO}_{2}$ dimer. As shown in Fig. $1, R_{\mathrm{cm}}$ is the distance between $X_{S}$-the center of mass of $\mathrm{SO}_{2}$, and $X_{P}$ the center of mass of propene. $\theta_{S}$ is the tilt angle of the $\mathrm{C}_{2}$ axis of $\mathrm{SO}_{2}$ with respect to $R_{\mathrm{cm}}$, and $\theta_{P}$ defines the tilt of the propene $X_{P} \mathrm{C}_{2}$ axis with respect to $R_{\mathrm{cm}}$. Dihedral angles $\psi_{S}$ and $\psi_{P}$ define the twist of the $\mathrm{SO}_{2}$ and propene planes, respectively. Finally, the dihedral angle $\phi$ is the torsional angle between the two monomers, defined as $\mathrm{O}_{B}-X_{5} X_{P}-\mathrm{C}_{2}$. The sign of the dihedral angles follows the definition in Ref. 15. These six structural parameters were varied in the least-squares fitting of the 24 moments of inertia. This resulted in two structures with reasonable fitting quality. These two structures are summarized in Table III. The only significant difference between these two structures involves the torsional angle $\phi$. The torsional angles (absolute values) are the supplement of each other, indicating that the difference in these two structures is a rotation of the two monomers relative to each other by $180^{\circ}$.

The different torsional angles signify two very different configurations. This is shown in Fig. 2 where the projections in the $b c$ inertial plane are illustrated. In order to
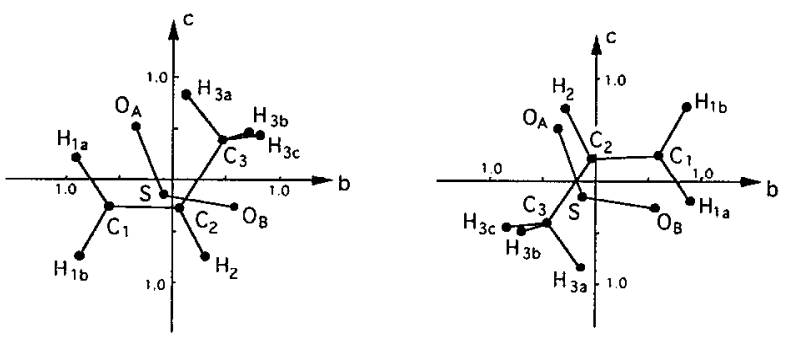

FIG. 2. The $b c$ plane projections of structures I and II. Structure I is preferred. 
TABLE IV. Principal axes coordinates $(\AA)$ of propene $\cdot \mathrm{SO}_{2}$ for structures I and II.

\begin{tabular}{|c|c|c|c|c|c|c|}
\hline & \multicolumn{2}{|c|}{$a$} & \multicolumn{2}{|c|}{$b$} & \multicolumn{2}{|c|}{$c$} \\
\hline & I & II & I & II & I & II \\
\hline $\mathrm{O}_{A}^{\mathrm{a}}$ & 1.284 & 1.295 & -0.688 & -0.744 & 1.079 & 1.053 \\
\hline$O_{B}$ & 1.247 & 1.250 & 1.216 & 1.157 & -0.494 & -0.524 \\
\hline $\mathbf{s}$ & 1.323 & 1.317 & -0.194 & -0.253 & -0.264 & -0.291 \\
\hline$X_{S}{ }^{\mathrm{b}}$ & 1.294 & 1.295 & 0.035 & -0.023 & 0.014 & -0.013 \\
\hline$X_{P}{ }^{\mathrm{c}}$ & -1.969 & -1.970 & -0.053 & 0.035 & -0.022 & 0.020 \\
\hline $\mathrm{C}_{1}$ & -1.763 & -1.778 & -1.211 & 1.196 & -0.522 & 0.519 \\
\hline $\mathrm{C}_{2}$ & -2.020 & -2.022 & 0.109 & -0.126 & 0.460 & 0.458 \\
\hline $\mathrm{C}_{3}$ & -2.116 & -2.102 & 0.884 & -0.906 & 0.821 & -0.822 \\
\hline $\mathrm{H}_{1 a}$ & -1.610 & -1.624 & -1.790 & 1.774 & 0.374 & -0.377 \\
\hline $\mathrm{H}_{1 b}$ & -1.704 & -1.730 & -1.725 & 1.713 & -1.471 & 1.468 \\
\hline $\mathrm{H}_{2}$ & -2.162 & -2.166 & 0.620 & -0.636 & -1.400 & 1.399 \\
\hline $\mathrm{H}_{3 a}$ & -1.952 & -1.937 & 0.239 & -0.261 & 1.686 & -1.687 \\
\hline $\mathbf{H}_{3 b}$ & -3.098 & -3.078 & 1.338 & -1.369 & 0.941 & -0.947 \\
\hline $\mathrm{H}_{3 c}$ & -1.373 & -1.351 & 1.677 & -1.692 & 0.865 & -0.859 \\
\hline
\end{tabular}

${ }^{a}$ See Fig. 1 for atom label definitions.

${ }^{b}$ Center of mass of $\mathrm{SO}_{2}$.

${ }^{c}$ Center of mass of propene.

choose a preferred structure in a case like this, a careful comparison of the coordinates of the substituted atoms determined from Kraitchman's equations ${ }^{16}$ vs the leastsquares fitted values is usually instructive. The latter values are given in Table IV. It is interesting that the least-squares values of the coordinates for the two structures are very close to each other for all thc atoms except that the $b$ and $c$ coordinates of propene have opposite signs. There are some noticeable differences in the $b$ coordinates of the $\mathrm{SO}_{2}$ atoms, otherwise the coordinates are quite indistinguishable. A check against the Kraitchman determined coordinates (Table $V$ ) indicates a preference for structure $I$, but the comparison is not very compelling. (This preference is likewise manifested in the better fit to the observed $I$ 's for structure I, cf. $\Delta I_{\text {rms }}$ in Table III). What occurs in the structure fitting is that a rotation of propene relative to $\mathrm{SO}_{2}$ by $180^{\circ}$ leads to remarkably little change in the absolute values of the principal axis coordinates for the two configurations. Since propene has no symmetry, this might be considered fortuitous. In actuality, it has a "near $\mathrm{C}_{2}$ axis" in an inertial sense since the $\mathrm{CH}_{3}$ and terminal $\mathrm{CH}_{2}$ group have similar masses. There is no apparent set of isotopically substituted species which is likely to resolve this ambiguity. At one stage we hoped that this was not the case and assigned the two doubly substituted $\mathrm{S}^{18} \mathrm{O}^{16} \mathrm{O} \cdot \mathrm{CH}_{3} \mathrm{CDCH}_{2}$ species with the expectation that a better match for the $b$ coordinates of the $\mathrm{SO}_{2}$ might result compared to the Kraitchman values. However, these data did not clearly resolve the ambiguity.

In the end, dipole moment data permitted a clear choice between the two structures. The vector sum of the dipole moments of $\mathrm{SO}_{2}$ and propene compare very well with the experimentally determined value for structure I while for structure II the comparison is much poorer. This is discussed in the next section. Additional support for structure $\mathrm{I}$ is obtained from an electrostatic energy calculation which gave a minimum close to structure I and a maximum close to structure II on the energy vs torsional angle curve. This will be discussed in the electrostatic calculation section. A side view projection of structure $I$ is illustrated in Fig. 3.

The uncertainties associated with structure I in Table III are the statistical values obtained from the least-squares fitting of the moments of inertia. The structure is the socalled $r_{0}$ structure and it is not easy to quantitatively estimate its deviation from the equilibrium structure $r_{e}$ without correction of the moments for vibrational effects. Given the large amplitude nature of these internal motions in weakly bonded complexes, the vibrational effects could be sizeable. We recommend that $R_{\mathrm{cm}}$ and the angles should be within $0.05 \AA$ and $5^{\circ}$ of the equilibrium values.

\section{Dipole moments}

The Stark effect of nine $M$ components from five different transitions was measured. The second order Stark coefficients are available as supplementary data. ${ }^{13}$ All the splittings have been checked carefully to ensure strictly second order behavior. Least-squares fit of the observed Stark coefficients to those calculated from the rotational

TABLE V. Comparison of the atomic coordinates from least-squares fit for structures I and II and Kraitchman substitution calculations.

\begin{tabular}{lllll}
\hline \hline & & Structure I & Structure II & Kraitchman \\
\hline $\mathrm{O}_{A}$ & $|a|$ & $1.284 \AA$ & $1.295 \AA$ & $1.276 \AA$ \\
& $|b|$ & 0.688 & 0.744 & 0.657 \\
& $|c|$ & 1.079 & 1.053 & 1.092 \\
$\mathrm{O}_{B}$ & $|a|$ & 1.247 & 1.250 & 1.244 \\
& $|b|$ & 1.216 & 1.157 & 1.194 \\
& $|c|$ & 0.494 & 0.524 & 0.507 \\
$\mathrm{~S}$ & $|a|$ & 1.323 & 1.317 & 1.291 \\
& $|b|$ & 0.194 & 0.253 & 0.222 \\
& $|c|$ & 0.264 & 0.291 & 0.280 \\
$\mathrm{H}_{2}$ & $|a|$ & 2.162 & 2.166 & 2.162 \\
& $|b|$ & 0.620 & 0.636 & 0.624 \\
& $|c|$ & 1.400 & 1.399 & 1.369 \\
\hline \hline
\end{tabular}



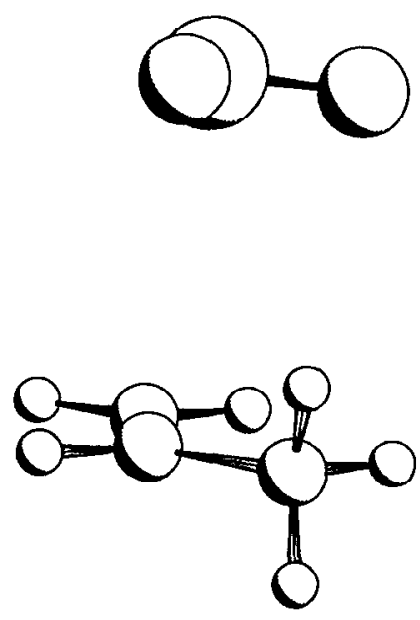

FIG. 3. Structure $I$ in the $a c$ plane.

constants gave $\mu_{a}=0.476(3) \mathrm{D}, \mu_{b}=0.697(38) \mathrm{D}, \mu_{c}$ $=1.040(24) \mathrm{D}$, and a total dipole moment of $\mu_{T}$ $=1.340(27) \mathrm{D}$.

These values can be compared with those calculated from the vector sum of the dipole moments of $\mathrm{SO}_{2}$ and propene for the two structures discussed above. The dipole moment of $\mathrm{SO}_{2}$ has been determined as $1.633 \mathrm{D}^{11}$ from $X_{S}$ to $S$ (negative to positive). For propene the value of $\mu=0.364 \mathrm{D}$ was determined by Lide and Mann. ${ }^{17}$ They gave the orientation of the dipole moment as either $17^{\circ}$ or $33^{\circ}$ relative to the $\mathrm{C}-\mathrm{C}$ single bond without specifying the positive and negative ends. We calculated the dipole moment for propene using the CADPAC $a b$ initio program ${ }^{18}$ with a $6-31 G^{* *}$ basis sets. The calculated value is in good agreement with the experimental value and closer to the $33^{\circ}$ direction, which was also favored by Lide and Mann. The calculation indicated the sign of the dipole should be from $C_{1}$ to $C_{3}$ (negative to positive). With these results, we calculated the vector sums for structures I and II listed in Table VI. It is apparent that structure I has a much better agreement with the experimental values than structure II. This is convincing evidence to eliminate structure II. In essence the dipole moments of the monomers in structure I are aligned more nearly antiparallel which is energetically preferred. The differences between the values of structure I and the observed values arise in part from induction and vibrational averaging effects. It is normal behavior based on other $\mathrm{SO}_{2}-\pi$ systems that the $\mu_{a}$ component in the complex usually increases by a large amount while the $\mu_{b}$ and/or $\mu_{c}$ components decrease by small amounts.

\section{Electrostatic and ab initio calculation}

In order to determine whether an elcctrostatic interaction model can rationalize the structure of the propene $\cdot \mathrm{SO}_{2}$ complex, a distributed multipole analysis along the lines of Buckingham and Fowler ${ }^{19,20}$ was explored. In this model, the charge distribution of each monomer is described by sets of point multipoles, which are located on the atoms and sometimes at bond midpoints. In this simple physical model, only the electrostatic inter-
TABLE VI. Comparison of observed dipole components with values predicted for structures I and II.

\begin{tabular}{llll}
\hline & I & II & obs. \\
\hline$\left|\mu_{a}\right|$ & $0.079 \mathrm{D}$ & $0.054 \mathrm{D}$ & $0.476(3) \mathrm{D}$ \\
$\left|\mu_{b}\right|$ & 0.735 & 1.340 & $0.697(38)$ \\
$\left|\mu_{c}\right|$ & 1.064 & 1.448 & $1.040(24)$ \\
$\mu_{T}$ & 1.296 & 1.974 & $1.340(27)$ \\
\hline
\end{tabular}

action between the monomers is considered. Buckingham and Fowler also incorporate a short range repulsion, described by an atom hard sphere term. The distributed multipole values for $\mathrm{SO}_{2}$ were taken directly from Ref. 20 . Those for propene were determined by an $a b$ initio calculation using the CADPAC program ${ }^{18}$ with a $6-31 G^{* *}$ basis set. These multipole moments (Table VII) were then used to calculate the electrostatic interaction energy between the two monomers. Starting with structure I in Table III and holding all the fitted parameters fixed except for the torsional angle $\phi$, the energy versus $\phi$ curve in Fig. 4 was obtained. This gave a minimum $(-2.5 \mathrm{kcal} / \mathrm{mol})$ at $55^{\circ}$ near the experimental value of $60^{\circ}$ for structure I and a maximum $(-0.8 \mathrm{kcal} / \mathrm{mol})$ near structure II.

We have also calculated the electrostatic energy as a function of the tilt angle of $\mathrm{SO}_{2}\left(\theta_{S}\right)$ and of propylene $\left(\theta_{P}\right)$ with the other structural parameters fixed to those of structure I (neglecting repulsions). These two calculated curves are shown in Fig. 5. For both tilt angles, the calculated and observed minima values are within $10^{\circ}-15^{\circ}$ of each other. The electrostatic model gave similar agreement for several other $\mathrm{SO}_{2}$ systems, including ethylene $\cdot \mathrm{SO}_{2},{ }^{3}$ acetylene $\cdot \mathrm{SO}_{2},{ }^{4}$ benzene $\cdot \mathrm{SO}_{2},{ }^{5}$ and toluene $\cdot \mathrm{SO}_{2} \cdot{ }^{6}$ This simplified distributed multipole model appears to capture much of the interaction anisotropy for $\mathrm{SO}_{2} \cdot \pi$ complexes.

GAUSSIAN $90 a b$ initio calculations ${ }^{21}$ were explored to estimate the minimum energy configuration of the propene $\cdot \mathrm{SO}_{2}$ complex. The calculations were at the $\mathrm{HF} /$ SCF level with either a $4-31 \mathrm{G}$ or a $6-31 \mathrm{G}$ basis set. The six structural parameters described earlier were varied to search for the most stable structure. The initial values for the six parameters were taken from structure I. The structures with cither basis set were very similar while the 6-31G set gave a much larger stabilization energy. The optimized structure is in general agreement with the observed structure (Table VIII). This is similar to $a b$ initioexperimental comparisons for $\mathrm{SO}_{2}$ complexes with benzene, ${ }^{5}$ dimethylamine, ${ }^{22}$ trimethylamine, ${ }^{22}$ and dimethyl ether. ${ }^{23}$ We conclude that the interaction forces which determine the asymmetric structure, presumably electrostatic, are represented adequately enough in a quantum mechanical calculation at this level to give a reasonable prediction of the general configuration. One aspect which remains unexplored is whether the $a b$ initio calculation would quickly converge to this structure, or another minimum, if the initial structure was far from the experimental values.

A binding energy of $3.47 \mathrm{kcal} / \mathrm{mol}$ was obtained from the $a b$ initio energies for propene $\cdot \mathrm{SO}_{2}, \mathrm{SO}_{2}$ and propene 
TABLE VII. Atom coordinates and distributed multipole moments for $\mathrm{SO}_{2}$ and propene (a.u.). ${ }^{\mathrm{a}}$

\begin{tabular}{lccccccccrrr}
\hline & $x$ & $y$ & $z$ & $Q$ & \multicolumn{1}{c}{$\mu_{x}$} & \multicolumn{1}{c}{$\mu_{y}$} & \multicolumn{1}{c}{$\mu_{z}$} & $\theta_{x x}$ & \multicolumn{1}{c}{$\theta_{x y}$} & \multicolumn{1}{c}{$\theta_{y y}$} \\
\hline $\mathrm{S}$ & 0.000 & 0.6815 & 0.000 & 1.806 & 0.000 & -1.628 & 0.000 & 1.328 & 0.000 & -1.219 & -0.109 \\
$\mathrm{O}_{A}$ & 2.338 & -0.6815 & 0.000 & -0.580 & -0.031 & -0.011 & 0.000 & 0.273 & -0.384 & -0.221 & -0.052 \\
$A^{b}$ & 1.169 & 0.000 & 0.000 & -0.323 & -0.038 & 0.213 & 0.000 & 0.222 & -0.417 & 0.372 & -0.594 \\
$\mathrm{C}_{1}$ & 2.4062 & 0.1161 & 0.0000 & -0.0996 & 0.0500 & 0.0047 & 0.0000 & 0.0471 & -0.0482 & -0.0578 & 0.0107 \\
$\mathrm{C}_{2}$ & 0.0000 & 0.8802 & 0.0000 & -0.0088 & -0.1773 & -0.1390 & 0.0000 & 0.1190 & 0.2420 & -0.0800 & -0.0390 \\
$\mathrm{C}_{3}$ & -2.2327 & -0.8692 & 0.0000 & 0.0066 & 0.1752 & 0.1375 & 0.0000 & 0.1405 & 0.3418 & 0.0399 & -0.1804 \\
$\mathrm{H}_{1 a}$ & 2.8659 & -1.8937 & 0.0000 & 0.0241 & 0.0510 & -0.2065 & 0.0000 & 0.0315 & 0.0253 & -0.0758 & 0.0443 \\
$\mathrm{H}_{1 b}$ & 3.9507 & 1.4531 & 0.0000 & 0.0264 & 0.1619 & 0.1417 & 0.0000 & -0.0286 & -0.0670 & -0.0098 & 0.0384 \\
$\mathrm{H}_{2}$ & -0.4065 & 2.8995 & 0.0000 & 0.0230 & -0.0390 & 0.2069 & 0.0000 & 0.0442 & 0.0254 & -0.0809 & 0.0367 \\
$\mathrm{H}_{3 a}$ & -1.6372 & -2.8312 & 0.0000 & 0.0092 & 0.0513 & -0.1932 & 0.0000 & 0.0213 & 0.0280 & -0.0631 & 0.0418 \\
$\mathrm{H}_{3 b}{ }^{c}$ & -3.4199 & -0.5707 & -1.6753 & 0.0095 & -0.1138 & 0.0262 & -0.1606 & 0.0002 & 0.0101 & 0.0375 & -0.0377 \\
\hline \hline
\end{tabular}

${ }^{3}$ The distributed multipole moments for $\mathrm{SO}_{2}$ were taken from Ref. 20. Those for propene were calculated using CADPAC program with a 6-31G** basis set. Dipole moment directions are from regions of negative to positive charge. Atom labels from Fig. 1 . The multipole moment values for $\mathrm{O}_{B}$ and $\mathrm{H}_{3 c}$ follow by symmetry from $\mathrm{O}_{A}$ and $\mathrm{H}_{3 b}$.

$\mathrm{b} A$ is the midpoint of $\mathrm{S}-\mathrm{O}$ bond.

'The $\theta_{x z}$ and $\theta_{y z}$ values are zero for all the atoms except for $\mathrm{H}_{3 b}$, which are -0.0550 and 0.0108 , respectively.

with the $6-31 \mathrm{G}$ basis set. ${ }^{24}$ This is comparable to $2.92 \mathrm{kcal} /$ mol from the distortion constant $D_{J}$ using the pseudodiatomic (PD) model. ${ }^{25}$ The binding energy for several other $\mathrm{SO}_{2}-\pi$ complexes from the PD model are $1.1 \mathrm{kcal} / \mathrm{mol}$ for $\mathrm{C}_{2} \mathrm{H}_{2} \cdot \mathrm{SO}_{2},{ }^{4} 1.4 \mathrm{kcal} / \mathrm{mol}$ for $\mathrm{C}_{2} \mathrm{H}_{4} \cdot \mathrm{SO}_{2},{ }^{3} 1.9 \mathrm{kcal} / \mathrm{mol}$ for benzene $\cdot \mathrm{SO}_{2},{ }^{5} 2.4 \mathrm{kcal} / \mathrm{mol}$ for toluene $\cdot \mathrm{SO}_{2},{ }^{6}$ and $3.02 \mathrm{kcal} / \mathrm{mol}$ for butadiene $\cdot \mathrm{SO}_{2} \cdot{ }^{26}$ We believe that the $\mathrm{PD}$ values for the ethylene, propene, benzene, and toluene complexes are too low based on the experimental value for benzene $\cdot \mathrm{SO}_{2}$ of $4.4 \mathrm{kcal} / \mathrm{mol}$. Nevertheless, the $\mathrm{PD}$ (and $a b$ initio) values for butadiene $\cdot \mathrm{SO}_{2}$ agree well with the experimental value of $3.24 \mathrm{kcal} / \mathrm{mol} .{ }^{27}$ In any case, the relative $P D$ value for closely related systems are probably ordered correctly, suggesting that the binding energies for the propene and toluene complexes are about $0.5-1 \mathrm{kcal} /$ mol higher than for the ethylene and benzene complexes. This may come from a methyl group- $\mathrm{SO}_{2}$ interaction.

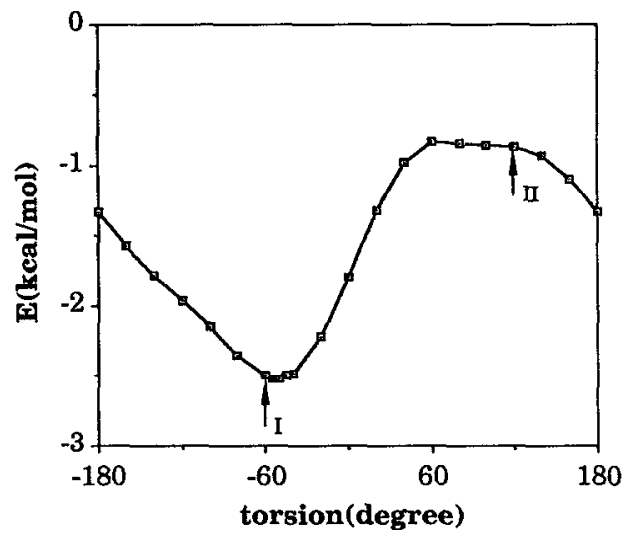

FIG, 4. The calculated electrostatic energy versus torsion angle $(\phi)$. The structure parameters (except $\phi$ ) are fixed to that of structure I. The arrows indicate the spectroscopic fitted values for structures I and II, respectively. The calculation shows that structure $I$ is close to the energy minimum and structure II close to maximum.

\section{E. Internal rotation}

Some of the transitions for propene $\cdot \mathrm{SO}_{2}$ have splittings of $10-25 \mathrm{kHz}$. We believe this splitting is caused by the internal rotation of the methyl group along its $\mathrm{C}_{3}$ axis, which has a barrier of $692 \mathrm{~cm}^{-1}$ in the propene monomer. ${ }^{17}$ Splittings for eight transitions of the propene $\cdot \mathrm{SO}_{2}$ normal species were fitted with a PAM internal rotation Hamiltonian. ${ }^{5,28}$ The quality of the fit $\left(\Delta v_{\mathrm{rms}}=5 \mathrm{kHz}\right)$ was good. The internal rotation barrier was determined from the fitting to be $690 \mathrm{~cm}^{-1}$. Since the splittings are very small, the value for the barrier may not be very accurate. The uncertainty is perhaps $\pm 10 \%$. Nevertheless, it is apparent that the barrier is not affected much upon complexation. This agrees with the electrostatic model for propene $\cdot \mathrm{SO}_{2}$ which gives a contribution to the barrier from complexation of only $61 \mathrm{~cm}^{-1}(0.17 \mathrm{kcal} / \mathrm{mol})$. This is the variation in the electrostatic energy as the methyl group is rotated. This can be compared to toluene $\cdot \mathrm{SO}_{2}$ where the methyl group internal rotation barrier increased by about $80 \mathrm{~cm}^{-1}$ upon complexation. ${ }^{6}$ Finally, the orien-

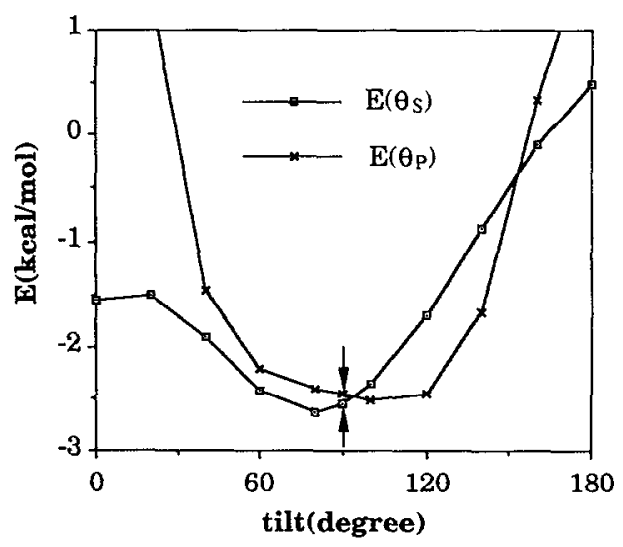

FIG. 5. The calculated electrostatic energy vs $\mathrm{SO}_{2}$ and propene tilt angles $\left(\theta_{S}\right.$ and $\theta_{P}$, respectively). $R_{\mathrm{cm}}, \psi_{S}, \psi_{P}, \phi$, and $\theta_{P}$ (or $\theta_{S}$ ) fixed at structure I values. The arrows indicate the spectroscopic fitted values. 
TABLE VIII. Comparison between the experimentally determined structure and the optimized structure from GAUSSIAN $90 a b$ initio calculation.

\begin{tabular}{lcccccc}
\hline \hline & $\theta_{S} / \mathrm{deg}$ & $\theta_{B} / \mathrm{deg}$ & $\psi_{S} / \mathrm{deg}$ & $\psi_{B} / \mathrm{deg}$ & $\phi / \mathrm{deg}$ & $R_{\mathrm{cm}} / \AA$ \\
\hline Least-squares fit & 93.1 & 96.3 & 89.9 & 82.1 & -60.1 & 3.2648 \\
GAUSSIAN 90/6-31G & 90.7 & 96.8 & 83.9 & 81.0 & -42.2 & 3.4264 \\
\hline \hline
\end{tabular}

tation of the methyl group in the complex was not determined. The moments of inertia are not sensitive to the methyl group torsional angle. An asymmetric $\mathrm{CH}_{2} \mathrm{D}-$ $\mathrm{CH}=\mathrm{CH}_{2}$ species would have to be assigned in order to determine the methyl top orientation. Given the high barrier in free propene and the small effect on the barrier upon complexation, it seems unlikely that the orientation of the methyl group changes much from free propenc.

\section{DISCUSSION}

This study was undertaken to ascertain how methyl group substitution on ethylene would affect the interaction with $\mathrm{SO}_{2}$. As noted above, the $\mathrm{SO}_{2}$ dipole moment $\left(\mathrm{C}_{2}\right.$ axis) has rotated by about $30^{\circ}$ from crossed to the $\mathrm{C}=\mathrm{C}$ bond in $\mathrm{C}_{2} \mathrm{H}_{4}$ to align nearly antiparallel to the dipole moment direction in propene. This structural feature and the variation in electrostatic energy with torsional angle (Fig. 4) provide compelling evidence that an electrostatic interaction model can rationalize the gross configuration of the propene $\cdot \mathrm{SO}_{2}$ complex. It is attractive to describe the near parallel planes structure as a result of sulfur $-\pi$ bond and oxygen-methyl group attractions. There are other structural features which suggest this: (a) the $\mathrm{SO}_{2}$ is pulled over to the methyl substituted carbon, however the sulfur remains oriented largely over the $\mathrm{C}=\mathrm{C}$ bond (Fig. 2); (b) one oxygen $\left(\mathrm{O}_{B}\right)$ makes a close contact to the out-of-plane methyl hydrogen, $R\left(\mathrm{O}_{B}-\mathrm{H}_{3 c}\right)=3 \AA$; (c) the twist angle of the propene $\left(\psi_{P}\right)$ is $82^{\circ}$, i.e., the double bond is tilted slightly towards the sulfur end of the $\mathrm{SO}_{2}$ moiety (Fig. 3).

The structural influence of a methyl group is also reflected in the toluene $\cdot \mathrm{SO}_{2}$ results. ${ }^{6}$ The toluene and $\mathrm{SO}_{2}$ dipole moments similarly line up in a more nearly antiparallel configuration. An oxygen-methyl group interaction is suggested: the $\mathrm{C}_{2}$ axis of $\mathrm{SO}_{2}$ forms a torsional angle of $47^{\circ}$ which aligns an $\mathrm{S}-\mathrm{O}$ bond approximately parallel to the $\mathrm{C}-\mathrm{CH}_{3}$ bond axis. A distributed multipole electrostatic model could similarly rationalize the observed torsional angle. A notable difference in the toluene $\cdot \mathrm{SO}_{2}$ interaction from propene $\cdot \mathrm{SO}_{2}$ is the greater tilt of the $\mathrm{SO}_{2}$ plane relative to toluene $\left(\sim 35^{\circ}\right)$.

The larger $\mathrm{SO}_{2}$ tilt angles in toluene $\cdot \mathrm{SO}_{2}$ and benzene $\cdot \mathrm{SO}_{2}\left(35^{\circ}-45^{\circ}\right)$ compared to propene $\cdot \mathrm{SO}_{2}$, and ethylene $\cdot \mathrm{SO}_{2}\left(8^{\circ}-14^{\circ}\right)$ may be associated in part with polarization effects. In all these complexes the $\mu_{a}$ dipole component is approximately aligned along $R_{\mathrm{cm}}$. It increases markedly compared to the vector sum expected from projection of the monomer values onto the $a$ inertial axis of the complex. This presumably arises largely from polarization of the hydrocarbon $\pi$ electrons by $\mathrm{SO}_{2} .{ }^{3}$ The increase in $\mu_{a}$ in ethylene $\cdot \mathrm{SO}_{2}$ and propylene $\cdot \mathrm{SO}_{2}$ is $0.3 \mathrm{D}$ and $0.4 \mathrm{D}$, respectively. In benzene $\cdot \mathrm{SO}_{2}$ and toluene $\cdot \mathrm{SO}_{2}, \mu_{a}$ increases by $0.5 \mathrm{D}$ and $0.6 \mathrm{D}$, respectively. The larger effects in the aromatic systems may be synergistically coupled to the greater tilting of the $\mathrm{SO}_{2}$ plane in order to better polarize the $\pi$ system. The small decreases in the $\mu_{b}$ and $\mu_{c}$ components are probably also explained by polarization effects from the $\mathrm{SO}_{2}$ inducing smaller antiparallel components along these axes (sce dipole moment section; the $b$ and $c$ axes lie approximately parallel to the carbon atom plane of the hydrocarbon).

One other structural effect associated with methyl group substitution is a decrease in $R_{\mathrm{cm}}$ from $3.50 \AA$ in the ethylene complex to $3.26 \AA$ in the propene complex. A similar shortening occurs in the benzene and toluene complexes: from 3.48 to $3.37 \AA$. These shortenings are presumably a reflection of a greater stabilization upon methyl substitution. This increased stability was estimated to be approximately $0.5-1 \mathrm{kcal} / \mathrm{mol}$ based on values for the dissociation energy estimated from centrifugal distortion constants.

Finally, the ethylene $\cdot \mathrm{SO}_{2}$ complex displayed prominent tunneling effects arising from torsional tunneling of the ethylene about $R_{\mathrm{cm}}$. This internal rotation barrier was estimated as $V_{2}=30 \mathrm{~cm}^{-1}$. Due to its asymmetry, internal rotation tunneling in propene $\cdot \mathrm{SO}_{2}$ to an equivalent form would require a net relative rotation of $360^{\circ}$. No evidence is found for such motion in the spectrum. If the electrostatic calculation is a useful guidc, the barricr is an order of magnitude larger than the ethylene complex. It is also noteworthy that the methyl group internal rotation barrier in propene $\left(V_{3}=692 \mathrm{~cm}^{-1}\right)$ is affected by less than $\pm 10 \%$ upon complexation.

In summary, the structures and binding energies of the propene $\cdot \mathrm{SO}_{2}$ and toluene $\cdot \mathrm{SO}_{2}$ complexes indicate that the methyl group increases the stability of the complexes compared to the ethylene and benzene analogs. This was previously inferred from electronic spectroscopy data. ${ }^{2(a)} \mathrm{Ap}$ parently this can be rationalized by increased attractive electrostatic interactions. This may arise in part from the higher polarity of the substituted hydrocarbon and from favorable oxygen-methyl group interactions.

\section{ACKNOWLEDGMENTS}

This work was supported by the National Science Foundation, Washington, D.C. The authors are grateful to the donors of the Petroleum Research Fund, administered by the American Chemical Society, for the support of this work. We are grateful for an allotment of computing time at the San Diego Supercomputing Center. 
${ }^{1}$ I. Hanazaki, J. Phys. Chem. 76, 1982 (1972); D. Booth, F. S. Dainton, and K. J. Ivin, Trans. Faraday Soc. 55, 1293 (1959).

${ }^{2}$ (a) L. J. Andrews and R. M. Keefer, J. Am. Chem. Soc. 73, 4169 (1951); (b) L. J. Andrews, Chem. Rev. 54, 713 (1954).

${ }^{3}$ A. M. Andrews, A. Taleb-Bendiab, M. S. LaBarge, K. W. Hillig II, and R. L. Kuczkowski, J. Chem. Phys. 93, 7030 (1990).

${ }^{4}$ A. M. Andrews, K. W. Hillig II, R. L. Kuczkowski, A. C. Legon, and N. W. Howard, J. Chem. Phys. 94, 6947 (1991).

${ }^{5}$ A. Taleb-Bendiab, K. W. Hillig II, and R. L. Kuczkowski, J. Chem. Phys. 97, 2996 (1992).

${ }^{6}$ A. Taleb-Bendiab, K. W. Hillig II, and R. L. Kuczkowski, J. Chem. Phys. 98, 3627 (1993).

${ }^{7}$ C. S. Marvel and E. D. Weil, J. Am. Chem. Soc. 76, 61 (1954).

${ }^{8}$ T. J. Balle and W. H. Flygare, Rev. Sci. Instrum. 52, 33 (1981).

${ }^{9}$ K. W. Hillig II, J. Matos, A. Scioly, and R. L. Kuczkowski, Chem. Phys. Lett. 133, 359 (1987).

${ }^{10}$ R. K. Bohn, K. W. Hillig II, and R. L. Kuczkowski, J. Phys. Chem. 93, 3456 (1989).

${ }^{11}$ D. Patel, D. Margolese, and T. R. Dyke, J. Chem. Phys. 70, 2740 (1979).

${ }^{12}$ J. K. G. Watson, J. Chem. Phys. 46, 1935 (1967).

${ }^{13}$ See AIP document No. PAPS JCPSA-100-15-3 for 3 pages of isotopic transition frequencies and second order Stark coefficients. Order by PAPS number and journal reference from American Institute of Physics, Physics Auxiliary Publication Service, 500 Sunnyside Boulevard, Woodbury, New York 11797-2999. The price is $\$ 1.50$ for each microfiche ( 60 pages) or $\$ 5.00$ for photocopies of up to 30 pages, and $\$ 0.15$ for each additional page over 30 pages. Airmail additional. Make checks payable to the American Institute of Physics.
${ }^{14}$ M. D. Harmony, V. W. Laurie, R. L. Kuczkowski, R. H. Schwendeman, D. A. Ramsay, F. J. Lovas, W. J. Lafferty, and A. G. Maki, J. Phys. Chem. Ref. Data 8, 619 (1979); D. R. Lide, Jr. and D. Christensen, J. Chem. Phys. 35, 1374 (1961).

${ }^{15}$ E. B. Wilson, Jr., J. C. Decius, and P. C. Cross, Molecular Vibrations (McGraw-Hill, New York, 1955).

${ }^{16} \mathrm{~J}$. Kraitchman, Am. J. Phys. 21, 17 (1953).

${ }^{17}$ D. R. Lide, Jr. and D. E. Mann, J. Chem. Phys. 27, 868 (1957).

${ }^{18}$ R. D. Amos and J. E. Rice, The Cambridge Analytic Derivatives Package, Issue 4.0 (Cambridge, England 1987).

${ }^{19}$ A. D. Buckingham and P. W. Fowler, J. Chem. Phys. 79, 6426 (1983).

${ }^{20}$ A. D. Buckingham and P. W. Fowler, Can. J. Chem. 63, 2018 (1985).

${ }^{21}$ M. J. Frisch, M. Head-Gordon, G. W. Trucks, J. B. Foresman, H. B. Schlegel, K. Raghavachari, M. Robb, J. S. Binkley, C. Gonzalez, D. J. Defrees, D. J. Fox, R. A. Whiteside, R. Seeger, C. F. Melius, J. Baker, R. L. Martin, L. R. Kahn, J. J. P. Stewart, S. Topiol, and J. A. Pople, GaUSSIAN 90-Revision I (Gaussian, Inc., Pittsburgh, PA, 1990).

${ }^{22}$ J. J. Oh, K. W. Hillig II, and R. I. Kucrkowski, J. Phys. Chem. 95, 7211 (1991).

${ }^{23}$ J. J. Oh, K. W. Hillig II, and R. L. Kuczkowski, Inorg. Chem. 30, 4583 (1991).

${ }^{24}$ The energies (a.u.) obtained with a 6-31G basis set were: propene, $-117.027409 ; \mathrm{SO}_{2},-546.903241$; propene $\cdot \mathrm{SO}_{2},-663.936181$.

${ }^{25}$ D. J. Millen, Can. J. Chem. 63, 1477 (1985).

${ }^{26}$ L.-W. Xu, A. Taleb-Bendiab, L. Nemes, and R. L. Kuczkowski, J. Am. Chem. Soc., 115, 5723 (1993).

${ }^{27}$ J. K. Grover, E. A. Walters, J. K. Newman, and M. G. White, J. Am. Chem. Soc. 107, 7329 (1985).

${ }^{28}$ C. C. Lin and J. D. Swalen, Rev. Mod. Phys. 31, 841 (1959). 